Ege Tıp Dergisi / Ege Journal of Medicine 2021; 60 (3): 219-229

\title{
Lipom eksizyonu sırasında stres küpü kullanımının ağrı ve anksiyete üzerine etkisi
}

\author{
The effect of using fidget cube on pain and anxiety during lipoma excision \\ Saliha Bozdoğan Yeşilot Hatice Çiftçi (1) Mehmet Kemal Yener \\ Çukurova Üniversitesi Sağıık Bilimleri Fakültesi Hemşirelik Bölümü, Adana, Türkiye
}

\section{ÖZ}

Amaç: Lokal anestezi altında gerçekleştirilen cerrahi işlemlerde bireylerde oluşan ağrı ve anksiyete yönetilmesi gereken önemli sağlık bakım sorunlarındandır. Bu araştırma lipom eksizyonu sırasında stres küpü kullanılarak dikkati başka yöne çekmenin ağrı ve anksiyete üzerine etkisinin değerlendirilmesi amacı ile gerçekleştirilmiştir.

Gereç ve Yöntem: Araştırma 1 Ekim 2019-1 Mart 2020 tarihleri arasında gerçekleştirilmiştir. Lokal anestezi altında lipom eksizyonu yapılacak, 18 yaşından büyük, yeterli görme, işitme ve konuşma işlevlerine sahip, Türkçe bilen, çalışmaya katılmayı kabul eden bireyler çalışmaya dahil edilmiştir. Verilerin toplanmasında Kişisel Bilgi Formu, Durumluk Kaygı Envanteri ve Sayısal Derecelendirme Ölçeği kullanılmıştır. Çalışma müdahale grubunda 46 kontrol grubunda 46 olmak üzere toplam 92 bireyle gerçekleştirilmiştir. Müdahale grubu lipom eksizyonu sırasında stres küpü kullanmış, kontrol grubu hastanedeki rutin tedavisini almıştır.

Bulgular: Katılımcıların \%68,5'i erkek, \%31,5'i kadındır. Araştırmaya katılan bireylerin yaş ortalaması müdahale $(41,67 \pm 11,48)$ ve kontrol $(44,59 \pm 13,83)$ grubunda benzerdir $(p=0,275)$. Eksizyon işlemi sırasındaki ağrı şiddeti ortalamaları bakımından müdahale $(2,67 \pm 1,69)$ ve kontrol $(4,46 \pm 2,82)$ grubu arasında istatistiksel anlamlı bir fark vardır $(p<0,001)$. Eksizyon işlemi öncesi müdahale $(38,63 \pm 5,24)$ ve kontrol $(40,39 \pm 6,04)$ grubunun anksiyete puan ortalamaları benzerdir $(p=0,139)$. Girişim sonrası gruplar arasında (Müdahale grubu=42,63 $\pm 5,26$; Kontrol grubu= 41,76 $\pm 5,50$ ) anksiyete puan ortalamaları arasında anlamlı fark yoktur $(p=0,440)$.

Sonuç: Bu araştırma sonucunda yapılan girişimin lipom eksizyonu sırasındaki ağrıyı azalttığı ancak anksiyete üzerine etkisinin olmadığı belirlenmiştir. Bu girişimin lokal anestezi altında gerçekleştirilen lipom eksiyonlarında işlem sırasındaki ağıının azaltılmasında rutin olarak kullanılması önerilmiştir.

Anahtar Sözcükler: Ağrı, anksiyete, lipom eksizyonu, distraksiyon.

\section{ABSTRACT}

Aim: Pain and anxiety that occur in individuals during surgical procedures performed under local anesthesia are important health care problems that need to be managed. This study aimed to evaluate the effect using fidget cube on pain and anxiety in patients during lipoma excision.

Material and Methods: This was a randomized controlled trial. The study was carried out between October 1, 2019, and March 1, 2020. Inclusion criteria for individuals were that they were over 18 years old and agree to take part in this study, undergoing lipoma excision with local anesthesia, having sufficient vision, hearing, and speech functions, speaking Turkish. Personal Information Form, State Anxiety Inventory, and Numeric Rating Scale were used to collect data.

\footnotetext{
Sorumlu yazar: Saliha Bozdoğan Yeşilot

Çukurova Üniversitesi Sağlık Bilimleri Fakültesi Hemşirelik

Bölümü, Adana, Türkiye

E-posta: saliha81bozdogan@gmail.com

Başvuru tarihi: 29.07.2020

Kabul tarihi: 19.01.2021
} 
Ethics committee permission was obtained. The study was performed with a total of 92 individuals, 46 of them were intervention group and the rest were control group. The intervention group used fidget cube additionally during lipoma excision, and the control group took only routine treatment in the hospital.

Results: $68.5 \%$ of the participant was male and $31.5 \%$ was female. The mean age of the participants was similar in the intervention (41.67 \pm 11.48$)$ and the control $(44.59 \pm 13.83)$ groups $(p=0.275)$. There

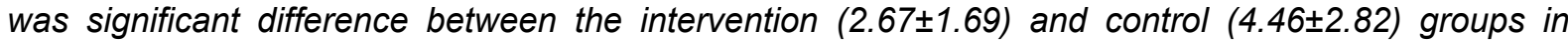
terms of the mean pain intensity during the excision procedure $(p<0.001)$. The means of anxiety

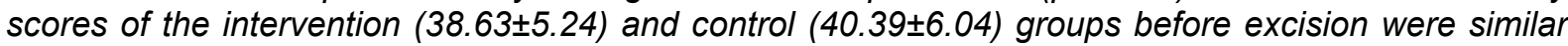
$(p=0.139)$. There was no significant difference between the means of anxiety scores (Intervention group $=42.63 \pm 5.26$; Control group 41.76 \pm 5.50$)$ after intervention $(p=0.440)$.

Conclusion: In this study it was determined that the intervention reduced the pain during lipoma excision but had no effect on participants' anxiety. It has been suggested that this intervention should be used routinely for managing the pain during the procedure.

Keywords: Pain, anxiety, lipoma excision, distraction.

\section{GiRiş}

Lipomlar, ince bir fibröz kapsülle çevrilmiş matür yağ hücreleri olup yetişkinlerde en sık görülen iyi huylu, genellikle asemptomatik tümörlerdir. Sıklıkla cilt altı ya da yüzeyseldirler. Derin lipomlar daha az görülmektedir (1, 2). Yuvarlak, oval ya da multi lobüle olabilirler. Etiyolojisi tam olarak bilinmemekle birlikte genetik faktörler ve travmaya sekonder gelişebileceği düşünülmektedir (1). Singh Sarla'nın lipomların epidemiyolojisi üzerine yapılmış bir çalışmasında; lipomların daha çok erkeklerde, 31-60 yaş grubunda yaygın olarak görüldüğü, sıklıkla baş, boyun ve gövde bölgesinde ortaya çıktığı ve beş santimetreden küçük olduğu belirtilmiştir (3). Lipomların tanısı genellikle klinik olarak konulmaktadır. Tedavisinde temel seçenek cerrahi eksizyondur. Eksizyon, lokal anestezi ile günübirlik cerrahi işlem olarak gerçekleştirilmekte ve çoğunlukla lipomun iyileşmesi ile sonuçlanmaktadır $(1,4)$.

Cerrahi girişimler hastalarda anksiyete durumunu oluşturabilmektedir. Anksiyeteyi azaltıcı yöntemlere rağmen cerrahi girişim yapılacak olan hastaların \%75'inin anksiyete yaşadıkları çalışmalarda belirtilmiştir $(5,6)$. Özellikle bireylerin uyanık olduğu lokal anestezi ile gerçekleştirilen cerrahi işlemlerde, bedenin kesildiğini hissetme veya görme, ağrıyı deneyimleme ve kontrolünü kaybedeceği beklentisi anksiyete ve eşlik eden belirtileri oluşturabilen önemli durumlardır $(7,8)$. Literatürde cerrahi girişim ile anksiyete ve ağrı arasındaki ilişki birçok çalışmada gösterilmiş olup anksiyete arttıkça ağrının da arttığı belirtilmektedir (9-13). Melzack ve Wall (1965) tarafından geliştirilen Kapı Kontrol Teorisinde, yüksek düzey anksiyete yaşayan bireylerin ağrıya daha fazla duyarlı olduğu belirtilmiştir. Bu durumun kortikal aktivitedeki artışın sonucu olarak retiküler inhibisyon aktivitesindeki azalmayla ilişkili olduğu düşünülmektedir. Teoriye göre anksiyete azaltılabilirse sürecin tersine çalışması ve kapıların kapanarak ağrının azalması mümkündür (14). Melzack ve Wall (1965)'a göre ağrı subjektif bir deneyimdir. Algılama ve yorumlama gibi psikolojik faktörlerle ilişkilidir ve ağrı sembolik bir kapı mekanizması ile tanımlanmaktadır. Buna göre ağrı mesajları omurilikteki sinir kapılarından geçmektedir. Bu kapılar ağrının omurilikten beyne gitmesini engellemekte ya da izin vermektedirler. Teoriye göre ağrı; duyusal-ayırt edici, duygusalmotivasyonel ve bilişsel-değerlendirici boyutları içeren çok boyutlu bir deneyimdir (15-17). Kapıları açan faktörler; duygusal (anksiyete, endişe, kızgınlık, stres gibi), bilişsel (dikkatin ağrıya odaklanması) ve fiziksel (aktivite azlığı) faktörlerdir. Kapıları kapatan faktörler ise duygusal (rahatlama ve memnuniyet), bilişsel (ağrı dışında bir şeye odaklanma), fiziksel faktörler (aktivite) ve karşı-uyarım (sıcak- soğuk uygulama, masaj gibi) olarak sınıflandırılmıştır (18). Ağrı yönetimi farmakolojik ve farmakolojik olmayan yöntemlerle yapılmaktadır. Farmakolojik yöntemlerde ilaçlar yaygın olarak kullanılırken farmakolojik olamayan yönetmelerde ise sıcaksoğuk uygulama, vibrasyon, masaj gibi periferal teknikler, gevşeme, dikkati başka yöne çekme, müzik gibi Bilişsel-Davranışsal Teknikler ve akupunktur, plasebo, cerrahi tedavi gibi diğer teknikler olarak sınıflandırılmaktadır (19). Ağrı yönetiminde kullanılan bilişsel-davranışçı yöntemlerden dikkati başka yöne çekme, katılımcının pasif bir şekilde dikkatinin yeniden yönlendirilmesiyle ya da katılımcının yapılan göreve dahil edilmesiyle aktif olarak yapılabilmektedir (20). 
Dikkati başka yöne çekmeye dayanan bilişseldavranışçı girişimler, ameliyat öncesi, sırası ve sonrasında ağrı ve anksiyetenin azaltılmasında öncelikli olarak tercih edilmekte ve bu yöntemlerin olumlu etkileri bilinmektedir (21). Bu amaçla kullanılan yöntemlerden bazıları görselişitsel dikkat dağıtıcılar gibi pasif (22-24), video oyunları ve sanal gerçeklik uygulamaları gibi aktif dikkati başka yöne çekme teknikleridir (24-26). Hastalardaki ağrı ve anksiyete iyileşmeyi olumsuz etkilemekte ve taburculuğu geciktirebilmektedir (27). Buna karşın, hastaların ağrı ve anksiyetesi etkili biçimde yönetildiğinde kan basıncı, solunum sayısı ve ilaç kullanımının azaldığı, yaşam kalitesinin arttığı ve iyileşme süresinin kısaldığı gözlenmektedir $(28,29)$. Bununla birlikte farmakolojik olmayan yöntemlerin ağrı gidermede kullanılması ile analjeziklerin kullanım oranı azaltılmakta ve hastanın ağrı sorununun olabildiğince giderilerek yaşam kalitesi yükseltilmektedir. Bu yöntemlerin birey tarafından kolaylıkla uygulanabilir olması, analjezikler gibi yan etkilerinin olmaması ve bireye ekonomik yük getirmemesi gibi avantajları vardır (19).

Stresi azaltmaya yönelik yeni yöntemler geliştirildikçe bu yöntemlerin hastalar üzerindeki etkisi de araştırmalara konu olmaktadır. Stres küpü (Fidget cube), günlük yaşam içinde stresli hissedilen durumlarda kişilerin rahatlamak amacı ile farkına varmadan yaptığı parmak çıtlatma, dizlerini sallama, saçla oynama gibi davranış kalıplarına benzer davranışları oluşturmasına olanak sağlayabilen bir ürün olarak tasarlanmıştır (30). Küpün her bir yüzeyi kullanıcılara farklı hareket seçeneği sağlamaktadır. Kullanımı kolay, ulaşılabilir, pratik ve ekonomiktir. Hastaların stres küpünü kullanmasının kapı kontrol teorisine göre fiziksel, duygusal ve bilişsel açıdan etkileme potansiyeli vardır. Bu araştırmanın amacı, lokal anestezi altında lipom eksizyonu yapılan bireylerde stres küpü kullanarak uygulanan dikkatin başka yöne çekme yönteminin ağrı ve anksiyete üzerine etkisinin değerlendirilmesidir. $\mathrm{Bu}$ araştırmanın sonuçları, farklı malzemelerin aktif dikkati dağıtma yöntemi olarak kullanılması ve sonuçların kapı kontrol teorisine dayanarak açıklanması ile klinikte pratik, uygulanabilir ve ekonomik bir ağrı ve anksiyete yönetim tekniği sağlayabilir.

\section{GEREÇ ve YÖNTEM}

$\mathrm{Bu}$ araştırma tek merkezli, ön test-son test düzende randomize kontrollü deneysel bir çalışmadır. Çalışmanın raporlanmasında CONSORT ilkeleri kullanılmıştır. Araştırmanın verileri 1 Ekim 2019-1 Mart 2020 tarihleri arasında toplanmıştır. Lipomu olan bireyler, tanı ve tedavi için hastanenin Genel Cerrahi Polikliniğine başvurmakta ve orada ilk muayeneleri yapılmaktadır. Daha sonra lipom eksizyonu için uygun randevu tarihi belirlenmekte ve bu tarihte gelen hastaların hastaneye günübirlik yatış işlemleri yapılmaktadır. Belirlenen cerrahi işlem gününde, işlem öncesi hasta derleme alanında bekletilen hastalar sırayla ameliyathaneye alınarak lokal anestezi altında eksizyon işlemi gerçekleştirilmekte ve daha sonra ameliyat sonrası hasta derleme alanında dinlendirildikten sonra tedaviye ilişkin reçete verilerek taburcu edilmektedir. Hastanede lokal anestezi altında yapılan lipom eksizyonları için postoperatif dönemde bekleme süresine ilişkin belirli bir protokol olmamakla birlikte, hastaların durumu göz önüne alınarak minimum 30 dakika izlendikten sonra hastalar taburcu edilmektedirler.

\section{Araştırmanın Evreni}

Araştırmanın evrenini; Adana Şehir Eğitim ve Araştırma Hastanesi, Genel Cerrahi Bölümünde lokal anestezi altında lipom eksizyonu olacak tüm bireyler oluşturmuştur.

\section{Araştırmanın örneklemi}

Araştırmanın örneklemi lipom eksizyonu için gelen, araştırmaya alınma kriterlerine uyan ve araştırmaya katılmayı kabul eden 92 birey oluşturmuştur. Araştırmanın örneklemi, güç analizi yapılarak $G^{*}$ Power 3.1 programında hesaplanmıştır. Deneysel olarak tasarlanan çalışma için daha önce gerçekleştirilen benzer bir çalışma temel alınarak yapılan Power analizi (G*Power 3.1.9.2) sonucunda; girişim sonrası müdahale grubunda Anksiyete skoru ortalaması $45,19 \pm 6,66$, kontrol grubunda ise $49,18 \pm 6,81$ olarak verilmiştir. Bu değerlere göre yapılan değerlendirmede operasyon sonrası iki grup arasındaki etki büyüklüğü 0,5923 olarak alındığında Power: 0,80 , ve $\alpha$ : 0,05 için tespit edilen örneklem sayısı her bir grup için minimum 46 olmak üzere toplam 92 olarak saptanmıştır (31).

\section{Katılımcılar}

Araştırmaya alınma kriterleri; lokal anestezi altında lipom eksizyonu yapılacak, 18 yaşından büyük, yeterli görme, işitme ve konuşma işlevlerine sahip, Türkçe bilen, çalışmaya katılmayı kabul eden bireyler çalışmaya dahil edilmiştir.

Araştırmaya alınmama kriterleri; ellerini kullanmakla ilgili sorunu olan, diyabet tanısı olan (ağrı hissini etkilediği için), psikiyatrik ilaç 
kullanan (anksiyete durumunu etkileyeceği için), çalışmaya katılmaya gönüllü olmayan bireyler çalışmaya dahil edilmemiştir. Toplamda 180 birey değerlendirmeye alınmış olup 80 hasta araştırmaya dahil edilme kriterlerini karşılamadığı, sekiz hasta çalışmaya katılmayı kabul etmediği için araştırmaya dahil edilmemiştir. Araştırmaya katılmak istemeyen bireyler ilgi duymadıklarını belirtmiş̧lerdir. Toplamda 92 hasta ile çalışma tamamlanmıştır.

Uygulamayı sonlandırma kriterleri; cerrahi girişimin herhangi bir nedenle sonlandırılması gerektiğinde uygulamanın sonlandırılması planlanmıştır. Araştırma süresince cerrahi işlemin sonlandırılması gereken bir durum oluşmamıştır.

\section{Veri Toplama Form ve Araçları}

Kişisel Bilgi Formu: Konu ile ilgili literatür incelenerek araştırmacılar tarafından hazırlanan bireye ilişkin sosyo-demografik özelliklerle ilgili sorular (yaş, cinsiyet, medeni durum, öğrenim durumu, meslek vb.) ile yaşam bulguları (kan basıncı, nabız, solunum) ölçümü ve eksizyon işleminin ölçülen gerçek süresi ve birey tarafından algılanan eksizyon işlemi süresine ilişkin bilgilerden oluşmaktadır $(23,31)$.

Sayısal Derecelendirme Ölçeği (Numeric Rating Scale-NRS): Ağrı şiddetini belirlemeye yönelik olan bu yöntem, hastanın ağrısını sayılarla açıklamasını amaçlamaktadır. Sayısal Derecelendirme Ölçeğinde ağrı şiddeti, ağrı yokluğu (0) ile dayanılmaz ağrı (10) düzeyi arasında puanlanmaktadır (32).

Durumluk Kaygı Envanteri (State Anxiety Inventory -STAI-1): Envanter 1970 yılında Spielberger tarafından geliştirilmiş, Öner ve Le Compte tarafından 1983 yılında Türkçe formu uyarlanarak geçerlilik-güvenirlik çalışması yapılmıştır (33). Türkçe formun iç tutarlığı ve güvenirliği Kuder Richardson alfa güvenirliğinde Durumluk Anksiyete Ölçeği için 0,94 ile 0,96 arasında bulunmuştur. Ölçek 20 maddeden oluşmaktadır. Yanıtlar 1-4 arasında değişmektedir. Ölçekten elde edilen toplam puan değeri 20-80 arasındadır. Yüksek puan kaygı düzeyinin yüksek olduğunu göstermektedir (33). $\mathrm{Bu}$ araştırmada, işlem öncesi STAI-I için Cronbach alfa 0,90 , işlem sonrası için ise 0,88 olarak hesaplanmıştır.

\section{Müdahale}

\section{Müdahale Grubuna Yapılacak Uygulamalar}

Müdahale grubundaki bireylere eksizyon işlemi öncesi müdahale hakkında bilgi verilmiştir. Daha sonra ameliyat masasına alınan bireylere stres küpü verilerek küpün işlevleri tanıtılmıştır. Bireylere günlük yaşamda kendilerini stresli hissettiklerinde fark etmeden yaptıkları tespih çekme, düğme açma kapama, para sayma ve kalem çevirme gibi hareketleri yapabilecekleri gösterilmiştir. Böylece bireylerin küpün her bir yüzeyindeki hareketi seçme şansı olmuştur. Bu girişim, eksizyon işlemi sonlanıncaya kadar devam etmiştir. Girişim ortalama 16,09 $\pm 5,85$ dakika sürmüştür.

\section{Kontrol Grubuna Yapılacak Uygulamalar}

Kontrol grubundaki bireylere hastanede uygulanan rutin cerrahi eksizyon prosedürü uygulanmıştır. Bunun dışında herhangi bir girişim uygulanmamıştır.

Çalışmanın başlangıcında işlemden 15 dakika önce tüm bireylere Kişisel Bilgi Formu, NRS ve STAI-I uygulanmıştır. İşlem sırasında ağrı şiddeti cerrahi kesinin yapıldığı sırada NRS ile değerlendirilmiştir. Cerrahi işlemden 30 dakika sonra NRS ve STAI-I uygulanmıştır.

\section{Randomizasyon ve Körleme}

Müdahale ve kontrol gruplarının randomizasyonu research randomizer web sayfası kullanılarak belirlenmiştir (34). Bireyler bu web sayfasında sunulan tabloda gösterilen sıraya göre gruplara dahil edilmiştir. Eksizyon işlemi için hastane kaydı sırasında sekreterden içinde numaralar olan kapalı zarfları hasta dosyasına konulmuş bu zarflar steril ortamda müdahaleyi yapan araştırmacı tarafından bireyler çalışmaya katılmayı kabul ettikten sonra açılmıştır.

Yapılan dikkati başka yöne çekme uygulamasının özelliği gereği körleme mümkün olmamıştır. Bu nedenle veri toplama sürecinde körleme sağlanmıştır. Çalışmada, ön test ve son testler uzman hemşire olan yardımcı araştırmacı tarafından gerçekleştirilmiştir. Müdahale psikiyatri hemşireliği uzmanı araştırmacı tarafından ameliyathane içinde yürütülmüştür. Ön test ve son testleri yapan araştırmacı tarafından steril alan dışındaki yarı steril alan olan ameliyat öncesi hasta derleme alanı ve ameliyat sonrası hasta derleme alanında veri toplanmıştır. Böylece bireylerin hangi grupta olduğuna dair bilgi sahibi olmaması ve verilerin araştırmacılara körlenmesi sağlanmıştır. Verilerin istatistik programına girişi bağımsız bir araştırmacı tarafından analizler başka bir bağımsız araştırmacı tarafından yapılmıştır. Lipom eksizyonu ve işlem sırasındaki ağrının değerlendirilmesi araştırma süreci boyunca yardımcı araştırmacı olan genel cerrah tarafından gerçekleştirilmiştir. 


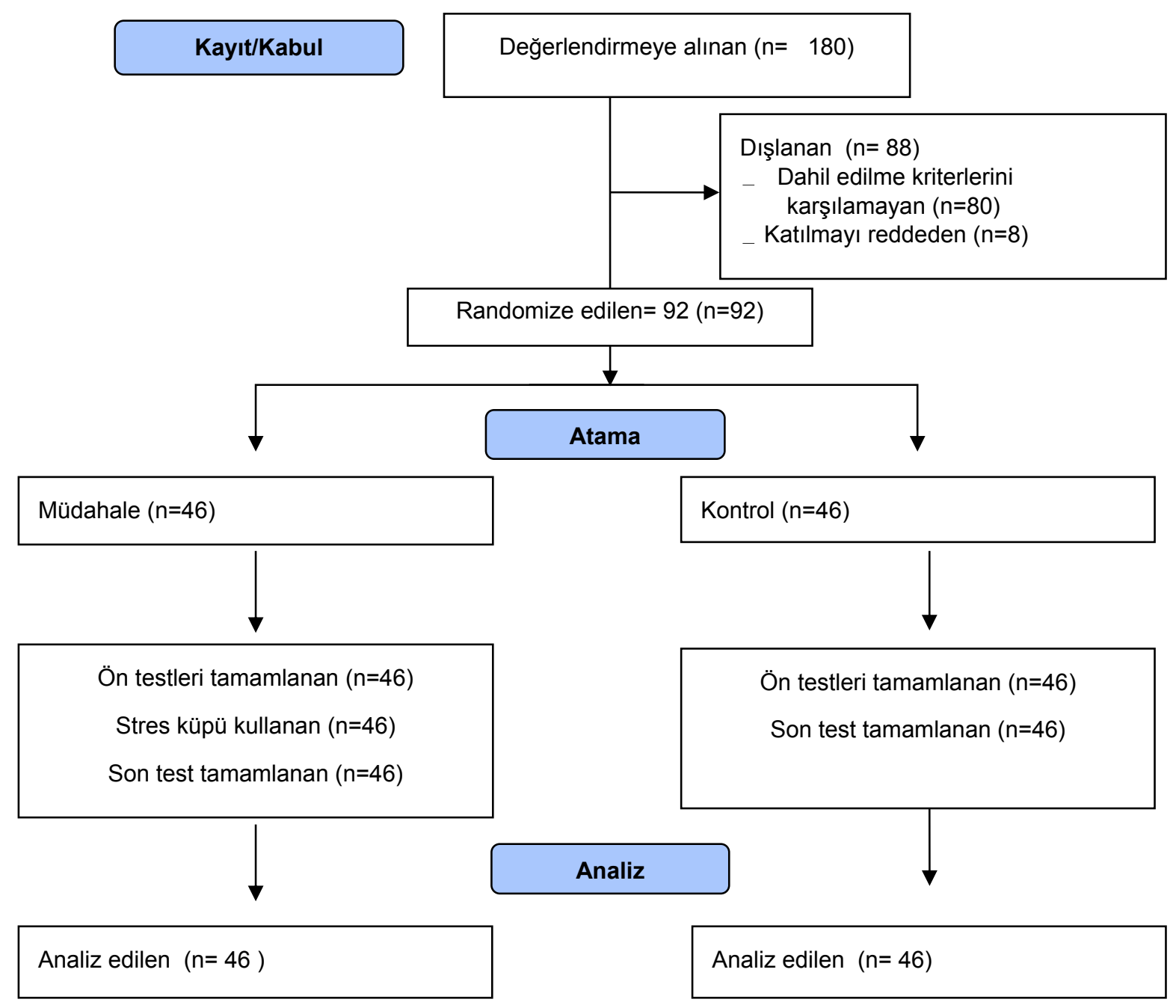

Şekil-1. CONSORT akış diyagramı.

\section{Etik Açıklamalar}

Araştırmanın yapılabilmesi için Adana Şehir Eğitim ve Araştırma Hastanesi Klinik Araştırmalar Etik Kurulu'ndan (27.02.2019/388) ve ilgili kurumdan gerekli izinler alınmıştır. Araştırmaya katılan bireylere Helsinki Bildirgesine uygun olarak araştırmanın amacı, gizlilik ve istedikleri zaman çalışmadan çekilebileceklerine ilişkin açıklama yapıldıktan bilgilendirilmiş onam alınmıştır.

\section{Verilerin Değerlendirilmesi}

Verilerin analizi SPSS 21 programında yapılmıştır. Sürekli değişkenlerin normallik kontrolü Shapiro Wilk testi ile yapılmıştır. Normal dağılıma uygunluk gösteren değişkenler için müdahale ve kontrol grubu arasında ortalama karşılaştırmasında Student's t test, işlem öncesi ve sonrası ortalama karşılaştırmasında Paired $t$ test, işlem öncesi ve sonrası farklarının gruplara göre karşılaştırmasında ise Tekrarlayan Ölçümlü Varyans Analizi (zaman x grup interaksiyonu) kullanılmıştır. Tanımlayıcı istatistikler ortalama, standart sapma, minimum ve maksimum değerlerle ifade edilirken, farklara ait \%95 güven aralıkları verilmiştir. Ağrı için etki büyüklüğü Cohen's d katsayısı ile değerlendirilmiştir. Normal dağılıma uygunluk göstermeyen değişkenler için ise müdahale ve kontrol grubu arasında medyan karşılaştırmasında Mann Whitney $U$ test kullanılmıştır. Tanımlayıcı istatistikler medyan ve çeyreklikler ile ifade edilmiştir. Kategorik değişkenlerin analizinden ise Ki-Kare testi kullanılmıştır. İstatistik anlamlılık seviyesi 0,05 olarak alınmıştır.

\section{BULGULAR}

Araştırma \%68,5'i erkek, \%31,5'i kadın olmak üzere toplam 92 bireyle tamamlanmıştır. 
Tablo-1. Müdahale ve kontrol grubunun sosyo-demografik özellikleri.

\begin{tabular}{|c|c|c|c|c|c|c|c|c|}
\hline \multirow[b]{2}{*}{ Özellikler } & & \multicolumn{2}{|c|}{ Müdahale Grubu } & \multicolumn{2}{|c|}{ Kontrol Grubu } & \multicolumn{2}{|l|}{ Toplam } & \multirow[b]{2}{*}{$p^{1}$} \\
\hline & & Ort $\pm S S$ & $\begin{array}{l}\text { Min- } \\
\text { Maks }\end{array}$ & Orttss & $\begin{array}{l}\text { Min- } \\
\text { Maks }\end{array}$ & Ort $\pm S S$ & $\begin{array}{l}\text { Min- } \\
\text { Maks }\end{array}$ & \\
\hline \multirow{2}{*}{ Yaş } & & $41,67 \pm 11,48$ & $20-77$ & $44,59 \pm 13,83$ & $18-78$ & $43,13 \pm 12,73$ & $18-78$ & 0,275 \\
\hline & & $\mathbf{n}$ & $\%$ & $\mathbf{n}$ & $\%$ & $\mathbf{n}$ & $\%$ & $p^{2}$ \\
\hline \multirow{2}{*}{ Cinsiyet } & Kadın & 14 & 30,4 & 15 & 32,6 & 29 & 31,5 & \multirow{2}{*}{0,882} \\
\hline & Erkek & 32 & 69,6 & 31 & 67,4 & 63 & 68,5 & \\
\hline \multirow{3}{*}{$\begin{array}{l}\text { Medeni } \\
\text { Durum }\end{array}$} & Evli & 12 & 26,1 & 10 & 21,7 & 22 & 23,9 & \multirow{2}{*}{0,625} \\
\hline & Bekar & 34 & 73,9 & 36 & 78,3 & 70 & 76,1 & \\
\hline & $\begin{array}{l}\text { Okuryazar } \\
\text { Değil }\end{array}$ & 1 & 2,2 & 2 & 4,3 & 3 & 3,3 & \multirow{4}{*}{0,840} \\
\hline \multirow{4}{*}{$\begin{array}{l}\text { Eğitim } \\
\text { Durumu }\end{array}$} & Okuryazar & 2 & 4,3 & 1 & 2,2 & 3 & 3,3 & \\
\hline & İlköğretim & 21 & 45,7 & 17 & 37,0 & 38 & 41,3 & \\
\hline & Lise & 12 & 26,1 & 14 & 30,4 & 26 & 28,3 & \\
\hline & $\begin{array}{l}\text { Yüksekokul ve } \\
\text { üstü }\end{array}$ & 10 & 21,7 & 12 & 26,1 & 22 & 23,9 & \multirow{6}{*}{0,180} \\
\hline \multirow{4}{*}{ Meslek } & Kamu & 9 & 19,6 & 10 & 21,7 & 19 & 20,7 & \\
\hline & Özel & 20 & 43,5 & 15 & 32,6 & 35 & 38,0 & \\
\hline & Emekli & 3 & 6,5 & 10 & 21,7 & 13 & 14,1 & \\
\hline & Çalışmıyor & 14 & 30,4 & 11 & 23,9 & 25 & 27,2 & \\
\hline \multirow{3}{*}{$\begin{array}{l}\text { Gelir } \\
\text { Durumu }\end{array}$} & $\begin{array}{l}\text { Gelir giderden } \\
\text { az }\end{array}$ & 19 & 41,3 & 21 & 45,7 & 40 & 43,5 & \\
\hline & $\begin{array}{l}\text { Gelir gidere } \\
\text { denk }\end{array}$ & 23 & 50,0 & 25 & 54,3 & 48 & 52,2 & \multirow[t]{2}{*}{0,123} \\
\hline & $\begin{array}{l}\text { Gelir giderden } \\
\text { fazla }\end{array}$ & 4 & 8,7 & 0 & 0,0 & 4 & 4,3 & \\
\hline \multirow{3}{*}{$\begin{array}{l}\text { Kronik } \\
\text { hastalık }\end{array}$} & Var & 6 & 13,0 & 8 & 17,4 & 14 & 15,2 & \multirow{2}{*}{0,562} \\
\hline & Yok & 40 & 87,0 & 38 & 82,6 & 78 & 84,8 & \\
\hline & Gövde & 24 & 52,2 & 26 & 56,5 & 50 & 54,3 & \\
\hline \multirow{3}{*}{$\begin{array}{l}\text { Ameliyat } \\
\text { bölgesi }\end{array}$} & Kol & 5 & 10,9 & 10 & 21,7 & 15 & 16,3 & \multirow{3}{*}{0,184} \\
\hline & Bacak & 5 & 10,9 & 1 & 2,2 & 6 & 6,5 & \\
\hline & Saçlı deri & 12 & 26,1 & 9 & 19,6 & 21 & 22,8 & \\
\hline \multirow{3}{*}{$\begin{array}{l}\text { Çocuk } \\
\text { Sahibi } \\
\text { Olma } \\
\text { Durumu }\end{array}$} & Evet & 36 & 78,3 & 37 & 80,4 & 73 & 79,3 & \multirow[b]{2}{*}{0,797} \\
\hline & Hayır & 10 & 21,7 & 9 & 19,6 & 19 & 20,7 & \\
\hline & & Medyan & $\begin{array}{l}\% 25- \\
\% 75\end{array}$ & Medyan & $\begin{array}{l}\% 25- \\
\% 75\end{array}$ & Medyan & $\begin{array}{l}\% 25- \\
\% 75\end{array}$ & $p^{3}$ \\
\hline $\begin{array}{l}\text { Çocuk } \\
\text { sayısı }\end{array}$ & & 2 & $1-3$ & 2 & $1-3$ & 2 & $1-3$ & 0,709 \\
\hline
\end{tabular}


Tablo-2. Müdahale ve kontrol grubunun ağrı şiddeti puan ortalamalarının dağılımı.

\begin{tabular}{|c|c|c|c|c|c|c|}
\hline \multirow{2}{*}{ Değişkenler } & & \multicolumn{2}{|c|}{ Müdahale Grubu } & \multicolumn{2}{|c|}{ Kontrol Grubu } & \multirow[b]{2}{*}{$p_{\text {grup }}$} \\
\hline & & OrttsS & $\begin{array}{l}\text { Min-Maks } \\
(\% 95 \mathrm{GA})\end{array}$ & Ort $\pm S S$ & $\begin{array}{l}\text { Min-Maks } \\
(\% 95 \text { GA) }\end{array}$ & \\
\hline \multirow{4}{*}{ Ağrı Şiddeti } & İşlem sırası & $2,67 \pm 1,69$ & $0-7$ & $4,46 \pm 2,82$ & $0-10$ & $<0,001$ \\
\hline & $\begin{array}{l}\text { İşlemden } 30 \text { dakika } \\
\text { sonra }\end{array}$ & $0,39 \pm 0,98$ & $0-4$ & $0,76 \pm 1,46$ & $0-7$ & 0,158 \\
\hline & Fark (\%95 GA) & $2,28 \pm 1,56$ & $1,82-2,75$ & $3,7 \pm 3,01$ & $2,8-4,59$ & $0,006^{*}$ \\
\hline & $\mathbf{p}_{\text {zaman }}$ & $<0,001$ & & $<0,001$ & & \\
\hline
\end{tabular}

$p_{\text {zaman: }}$ Paired t test, $p_{\text {grup }}$ Student's $t$ test, ${ }^{*} T e k r a r l a y a n$ Ölçümlü Varyans Analizi (zamanxgrup interaksiyonu)

Tablo-3. Müdahale ve kontrol grubunun STAI-I puan ortalamalarının dağılımı.

\begin{tabular}{|c|c|c|c|c|c|c|}
\hline \multirow[b]{2}{*}{ Değişkenler } & & \multicolumn{2}{|c|}{ Müdahale Grubu } & \multicolumn{2}{|c|}{ Kontrol Grubu } & \multirow[b]{2}{*}{$p_{\text {grup }}$} \\
\hline & & OrttSS & $\begin{array}{l}\text { Min-Maks } \\
\text { (\%95 GA) }\end{array}$ & Orttss & $\begin{array}{l}\text { Min-Maks } \\
(\% 95 \text { GA) }\end{array}$ & \\
\hline \multirow{4}{*}{ STAI-I } & $\begin{array}{l}\text { Eksizyon işlemi } \\
\text { öncesi }\end{array}$ & $38,63 \pm 5,24$ & $31-57$ & $40,39 \pm 6,04$ & $23-53$ & 0,139 \\
\hline & $\begin{array}{l}\text { Eksizyon işlemi } \\
\text { sonrası }\end{array}$ & $42,63 \pm 5,26$ & $27-51$ & $41,76 \pm 5,50$ & $30-53$ & 0,440 \\
\hline & Fark (\%95 GA) & $-4,00 \pm 6,25$ & $-5,86--2,14$ & $-1,37 \pm 5,48$ & $-3-0,26$ & $0,576^{*}$ \\
\hline & $\mathbf{p}_{\text {zaman }}$ & $<0,001$ & & 0,097 & & \\
\hline
\end{tabular}

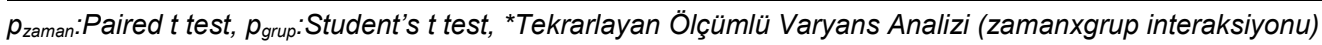

Tablo-4. Müdahale ve kontrol grubuna göre yaşam bulgularının dağılımı.

\begin{tabular}{|c|c|c|c|c|c|c|}
\hline \multirow{2}{*}{ Değişkenler } & & \multicolumn{2}{|c|}{ Müdahale Grubu } & \multicolumn{2}{|l|}{ Kontrol Grubu } & \multirow[b]{2}{*}{$p_{\text {grup }}$} \\
\hline & & Ortt土SS & $\begin{array}{l}\text { Min-Maks } \\
\text { (\%95 GA) }\end{array}$ & Ort $\pm S S$ & $\begin{array}{l}\text { Min-Maks } \\
(\% 95 \mathrm{GA})\end{array}$ & \\
\hline \multirow{4}{*}{$\begin{array}{l}\text { Sistolik Kan } \\
\text { Basıncı } \\
(\mathrm{mmHg})\end{array}$} & $\begin{array}{l}\text { İşlemden } 15 \text { dakika } \\
\text { Őnce }\end{array}$ & $133,89 \pm 15,98$ & $97-176$ & $134,54 \pm 17,53$ & $110-208$ & 0,853 \\
\hline & $\begin{array}{l}\text { İşlemden } 30 \text { dakika } \\
\text { sonra }\end{array}$ & $130,13 \pm 14,05$ & $109-166$ & $132,22 \pm 16,77$ & $109-205$ & 0,519 \\
\hline & Fark (\%95 GA) & $3,76 \pm 13,77$ & $-0,33-7,85$ & $2,33 \pm 10,56$ & $-0,81-5,46$ & $0,576^{*}$ \\
\hline & $p_{\text {zaman }}$ & 0,071 & & 0,142 & & \\
\hline \multirow{4}{*}{$\begin{array}{l}\text { Diyastolik } \\
\text { Kan Basıncı } \\
\text { (mmHg) }\end{array}$} & $\begin{array}{l}\text { İşlemden } 15 \text { dakika } \\
\text { Önce }\end{array}$ & $87,98 \pm 10,27$ & $55-110$ & $87,33 \pm 12,17$ & $64-118$ & 0,782 \\
\hline & $\begin{array}{l}\text { İşlemden } 30 \text { dakika } \\
\text { sonra }\end{array}$ & $84,93 \pm 9,79$ & $61-106$ & $84,61 \pm 13,12$ & $58-118$ & 0,893 \\
\hline & Fark (\%95 GA) & $3,04 \pm 11,53$ & $-0,38-6,47$ & $2,72 \pm 13,38$ & $-1,26-6,69$ & $0,901^{*}$ \\
\hline & $p_{\text {zaman }}$ & 0,080 & & 0,175 & & \\
\hline \multirow{4}{*}{ Nabız Sayısı } & $\begin{array}{l}\text { İşlemden } 15 \text { dakika } \\
\text { Őnce }\end{array}$ & $81,67 \pm 18,74$ & $15-115$ & $83,46 \pm 12,78$ & $60-115$ & 0,595 \\
\hline & $\begin{array}{l}\text { İşlemden } 30 \text { dakika } \\
\text { sonra }\end{array}$ & $78,20 \pm 10,91$ & $50-98$ & $73,20 \pm 13,25$ & $20-100$ & 0,051 \\
\hline & Fark (\%95 GA) & $3,48 \pm 16,13$ & $-1,31-8,27$ & $10,26 \pm 13,9$ & $6,13-14,39$ & $0,033^{*}$ \\
\hline & $p_{\text {zaman }}$ & 0,151 & & $<0,001$ & & \\
\hline \multirow{4}{*}{$\begin{array}{l}\text { Solunum } \\
\text { Sayısı }\end{array}$} & $\begin{array}{l}\text { İşlemden } 15 \text { dakika } \\
\text { Önce }\end{array}$ & $20,61 \pm 3,20$ & $14-28$ & $20,37 \pm 3,36$ & $16-28$ & 0,727 \\
\hline & $\begin{array}{l}\text { İşlemden } 30 \text { dakika } \\
\text { sonra }\end{array}$ & $19,24 \pm 2,65$ & $14-24$ & $17,83 \pm 3,51$ & $2-24$ & 0,032 \\
\hline & Fark (\%95 GA) & $1,37 \pm 2,68$ & $0,57-2,16$ & $2,54 \pm 3,83$ & $1,41-3,68$ & $0,092^{*}$ \\
\hline & $p_{\text {zaman }}$ & 0,001 & & $<0,001$ & & \\
\hline
\end{tabular}

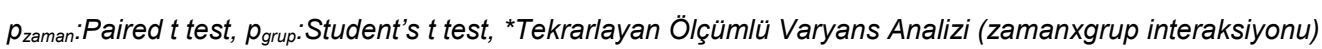


Tablo-5. Müdahale ve kontrol grubuna göre gerçek ve algılanan işlem sürelerin dağılımı.

\begin{tabular}{|c|c|c|c|c|c|}
\hline Doŭialanlar & Müdahale Grubu & & Kontrol Grubu & & \\
\hline Uegişkenier & Orttss & Min-Maks & Orttss & Min-Maks & $\boldsymbol{\rho}$ \\
\hline İşlem için beklenen süre & $69,2 \pm 37,41$ & 8-161 & $75,5 \pm 34,13$ & $6-145$ & 0,401 \\
\hline $\begin{array}{l}\text { Eksizyon işlemi gerçek } \\
\text { süre }\end{array}$ & $16,09 \pm 5,85$ & $7-30$ & $15,87 \pm 6,75$ & $6-38$ & 0,869 \\
\hline $\begin{array}{l}\text { Eksizyon işlemi algılanan } \\
\text { süre }\end{array}$ & $10,43 \pm 5,29$ & $1-25$ & $17,09 \pm 7,88$ & $5-30$ & $<0,001$ \\
\hline
\end{tabular}

p:Student's t test

Araştırmaya katılan bireylerin yaş ortalaması $43,13 \pm 12,73$ 'tür. Müdahale ve kontrol grubu arasında yaş ortalamaları, cinsiyet, medeni durum, eğitim durumu, meslek, gelir durumu, kronik hastalık varlığı, ameliyat bölgesi, çocuk durumu ve sayısı açısından gruplar benzerdir $(p>0,05)$ (Tablo-1).

Müdahale ve kontrol grubundaki bireylerin eksizyon işlemi öncesi ağrısı olmadığından ilişkili tabloya eklenmemiştir. Eksizyon işlemi sırasındaki ağrı şiddeti ortalamaları bakımından müdahale ve kontrol grubu arasında istatistiksel anlamlı bir fark vardır $(p<0,05)($ Tablo-2). İşlem sırasında ağrı şiddeti farkı için etki büyüklüğü (Cohen's d) 0,769 , işlem sonrası ağrı şiddeti farkı etki büyüklüğü (Cohen's d) 0,297 olarak hesaplanmıştır.

Girişim öncesi ve girişim sonrası STAI-I farkları müdahale ve kontrol grubu arasında farklılık göstermemektedir ( $p>0,05)$ (Tablo-3).

Girişim öncesi ve girişim sonrası nabız sayıları ortalamaları müdahale ve kontrol grubu arasında farklılık göstermektedir $(p<0,05)$ (Tablo-4).

Gruplara göre işlemi bekleme süresi ve işlem süresi ortalamaları farklılık göstermezken $(p>0,05)$, bireyler tarafından algılanan işlem süresi kontrol grubunda daha uzun tespit edilmiştir $(p<0,05)$ (Tablo-5).

\section{TARTIŞMA}

Bu araştırmada, stres küpü kullanılarak dikkati aktif olarak başka yöne çekmenin, lipom eksizyonu yapılan bireylerde ağrıyı azalttığı buna karşın anksiyete üzerine etkisinin olmadığı saptanmıştır. Literatürde aktif ve pasif dikkati başka yöne çekme tekniklerinin kullanıldığı çalışmalar mevcuttur $(26,35)$. Bununla birlikte aktif bir dikkati başka yöne çekme yöntemi olarak düşünülebilecek stres küpünün kullanıldığı bir çalışmaya rastlanmamıştır. Bu araştırma, stres küpü kullanılarak dikkati başka yöne çekme uygulamasının lokal anestezi altında lipom eksizyonu yapılan bireylerde kullanıldığı ilk çalışmadır.
Bu araştırma sonucunda, stres küpü kullanan müdahale grubu işlem sırasında daha az ağıı hissetmiştir. İşlem sırasındaki ağrı şiddeti farkının etki büyüklüğü yükseğe yakın orta derecededir (36). Literatürde stres küpü kullanılarak dikkati başka yöne çekmenin ağrı şiddetine etkisinin araştırıldığı çalışmalara rastlanmamıştır. Molleman ve ark. (37)'nın çalışmasında yüz ve el bölgesinde cerrahi işlem uygulanan hastalarda lokal anestezi uygulaması sırasında basit şekilde dikkati başka yöne çekmenin ağrıyı azalttığı gösterilmiştir.

Bununla birlikte, Hudson ve arkadaşlarının (23) hastaların uyanık halde olduğu cerrahi işlemlerde dikkati başka yöne çekme amacı ile müzik, video izleme, iletişim ve stres topu kullanma şeklinde dört farklı aktif ve pasif distrasksiyon yöntemini karşılaştırdıkları çalışmalarında, işlem sırasında stres topu kullanan grubun video izleyen, müzik dinleyen ve kontrol grubuna göre ağrı düzeyinin anlamlı derecede az olduğu bildirilmiştir. Benzer şekilde, stres topu kullanılarak yapılan bir diğer çalışmada da stres topu kullanan grubun daha az ağrı hissettiği bulunmuştur (38). Buna karşın Gezginci ve ark. (39) tarafından taş kırma işleminde stres topu ve müzik kullanarak dikkati dağıtmanın ağrı ve anksiyete üzerine etkisinin araştırıldığı çalışmada, bu dikkati başka yöne çekme yöntemlerin ağrıya etkisinin olmadığı gösterilmiştir. Kapı kontrol teorisine göre; rahatlama ve memnuniyet duygusal olarak, ağrı dışında bir şeye odaklanma bilişsel olarak, cismin santral sinir sistemine etkisi fiziksel olarak kapıları kapatmakta ve böylece ağrıyı azaltmaktadır (18). Stres küpü, stresli durumlarda bireylerin elleri ile yaptıkları çeşitli hareketleri yapmayı sağlaması ile duygusal olarak, ağrı dışında küpün kendisi ve eldeki hareketlerle zihinsel meşguliyet bilişsel olarak ve küpün cisim olarak sinir iletileriyle santral sistemine etkisiyle de fiziksel olarak ağrıyı azaltmada etkili olmuş olabilir. Bununla birlikte teoriye göre ağrı 
dışındaki sinir uyarıları beyne ulaşmaya çalışan ağrı uyaranları ile yarışmaktadır. Ağrıyla ilgili olmayan akımların sayısının arttırılmasıyla ağrıyla ilgili akımların geçişi azaltılmaktadır (32). Buna göre stres küpünün duygusal, bilişsel ve fiziksel kapıları kapatıcı etkilerinin bir arada oluşturduğu etki, ağrıyla ilgili olmayan uyaranların daha fazla olmasını sağlayarak ağrıyla ilgili akımların geçişini azaltmış olabilir.

$\mathrm{Bu}$ çalışmada yapılan girişimin hastaların anksiyete düzeyine etkisinin olmadığı görülmüştür. Gezginci ve arkadaşlarının (39) taş kırma sırasında stres topu ve müziğin etkisini değerlendirdikleri çalışmalarında stres topunun bireylerin anksiyete düzeyini azaltmadığı bulunmuştur. Benzer şekilde, Yanes ve ark.'nın (40) cilt kanserinde cilt eksizyon sırasında stres topu ve el tutma girişiminin anksiyeteye etkisini araştırdıkları çalışmada yapılan girişimlerin anksiyete üzerine etkisinin olmadığı saptanmıştır. Ayrıca, Hudson ve Ogden'in (23) lokal anestezi ile yapılan ameliyatlar esnasındaki ağrı ve anksiyeteyi azaltmak amacı ile yapılan girişimlerin etkilerini değerlendirdiği meta-analiz çalışmasında anksiyeteyi azaltmak için relaksasyon temelli uygulamaların daha etkili olduğu belirtilmiştir. Anksiyete kontrol edilemezlik ve tehlikeyle ilgili inançlarda ortaya çıkan güçlü bir duygusal tepkidir (41). Bireylerin beklentilerinden, tehlike algısından, yorumlarından, bilişsel çarpıtmalarından etkilenebilecek bir duygudur (42). Bu çalışmaya katılan bireyler lokal anestezi altında, uyanık halde, ameliyathane ortamında gerçekleştirilen lipom eksizyonu sırasında kendi algılama ve yorumlama biçimleriyle maruz kaldıkları strese yanıt vermektedirler. Bu çalışmada, stres küpü kullanılarak yapılan el hareketlerinin getirdiği rahatlama ve dikkatin zararsız bir uyarana çekilmesi hastaların anksiyete düzeyini azaltmaya yetmemiş olabilir.

$\mathrm{Bu}$ çalışma sonucunda müdahale grubundaki bireylerin nabız sayıları ortalaması kontrol grubuna göre anlamlı şekilde düşmüştür. Ağrı şiddeti ile nabız sayısı arasında pozitif ilişki vardır (43). Bu çalışmada müdahale grubundaki anlamlı azalma ağrıdaki azalmanın etkisi ile olabilir. Objektif bir şekilde ölçülebilir olması yönü ile nabızdaki anlamlı düşüş önemlidir.
Ağrı ve anksiyete zaman algısını değiştirmektedir. Bireyler ağrılı olduklarında geçen zamana ilişkin algıları bozulmakta ve dikkatin başka yöne çekilmesi bireylerin zamanı algılamasını olumlu şekilde etkilemektedir (4447). Aynı zamanda ağrıyı azaltan uygulamaların zaman algısındaki değişimi azalttığı gösterilmiştir (48). Bu çalışmada da müdahale grubu yapılan cerrahi işlemin süresini gerçekte olduğundan daha kısa algılarken kontrol grubu daha uzun algılamıştır. Algılanan zamana ilişkin bu etki, müdahale grubundaki bireylerde stres küpünün dikkatini işlemden uzaklaştırarak, ağrının hoş olmayan etkisinin azaltılmasıyla ilişkili olabilir.

\section{SONUÇ}

$\mathrm{Bu}$ araştırmada, lipom eksizyonu sırasında stres küpü kullanımının bireylerde ağrı düzeyini azalttığı buna karşın anksiyete üzerine etkisinin olmadığı belirlenmiştir. Girişim işlem süresinin daha kısa algılanmasını sağlamıştır. $\mathrm{Bu}$ sonuçlara göre öneriler şu şekildedir:

Stres küpü kullanımı kolay, pratik ve ekonomiktir. Lokal anestezi altında lipom eksizyonlarında işlem sırasındaki ağrının azaltılmasında rutin olarak kullanılabilir.

Stres küpü kullanılarak dikkatin başka yöne çekilmesi yöntemi lokal anestezi ile yapılan farklı cerrahi işlemler sırasındaki ağrı şiddetine etkisi araştırılabilir.

Lokal anestezi altında lipom eksizyonu nedeni ile yaşanan anksiyete için farklı dikkati başka yöne çekme yöntemleri denenebilir.

\section{Araştırmanın sınırlılıkları}

$\mathrm{Bu}$ araştırmada işlem sırasındaki anksiyete düzeyi ve yaşam bulgularının değerlendirilmemiş olması bu araştırmanın sınırlıı̆̆ıdır. Bununla birlikte anksiyete durumunu etkileyebilecek işlemle ilgili tehlike algısı, beklentileri, bilişsel çarpıtmalarına ilişkin değerlendirmelerin olmaması ve anksiyetenin tek bir ölçekle değerlendirilmiş olması bu araştırma açısından bir sınırlılıktır.

Çıkar çatışması: $\quad \mathrm{Bu}$ çalışmanın gerçekleştirilmesi için herhangi bir mali destek alınmamıştır. Yazarlar arasında çıkar çatışması yoktur. 


\section{Kaynaklar}

1. Brunicardi FC, Andersen DK, Billiar TR, Dunn DL, Hunter JG, Matthews JB, Pollock RE. Schwartz cerrahinin ilkeleri. Çev. Özmen M. 10. Basım. Ankara: Güneş tıp kitapevi; 2015.

2. Ericson LA. Lipoma. Mayo Clin Proc 2019; 94 (1): 176-7.

3. Singh Sarla G. Epidemiology of subcutaneous lipomas. OTSBD 2019; 4 (3): 350-359.

4. Salam GA. Lipoma excision. American Family Physician 2002; 65 (5): 901-04

5. De Oliveira GS, Holl JL, McCarthy RJ, et al. Overestimation of mortality risk and preoperative anxiety in patients undergoing elective general surgery procedures: a propensity matched analysis. Int J Surg 2014; 12 : 1473-77.

6. Robleda G, Sillero-Sillero A, Puig T, Gich I, Baños JE. Influence of preoperative emotional state on postoperative pain following orthopedic and trauma surgery. Rev Lat Am Enfermagem 2014; $22: 785-91$.

7. Mitchell, M. Patient anxiety and conscious surgery. Journal of Perioperative Practice 2009; 19 (6): $168-73$.

8. Hudson BF, Ogden J, Whiteley MS. A thematic analysis of experiences of varicose veins and minimally invasive surgery under local anaesthesia. Journal of Clinical Nursing 2015; 1502-12. doi: 10.1111/jocn.12719.

9. Ocalan R, Akin C, Disli ZK, Kilinc T, Ozlugedik S. Preoperative anxiety and postoperative pain in patients undergoing septoplasty. B-ENT 2015; 11 (1): 19-23.

10. Navarro-Gastón D, Munuera-Martínez PV. Prevalence of preoperative anxiety and its relationship with postoperative pain in foot nail surgery: a cross-sectional study. International Journal of Environmental Research and Public Health 2020;17: 4481. doi:10.3390/ijerph17124481.

11. Wetsch WA, Pircher I, Lederer W, et al. Preoperative stress and anxiety in day-care patients and inpatients undergoing fast-track surgery. Br J Anaesth 2009; 103 (2): 199-205.

12. Carr ECJ, Thomas V. Patient experiences of anxiety, depression and acute pain after surgery: A longitudinal perspective.Int J Nurs Stud 2005; 42: 521-30.

13. Drahota A, Galloway E. Audiovisual distraction as an adjunct to pain and anxiety relief during minor surgery. Foot 2008; 18: 211-19.

14. Adams N, Field L. Pain management 1: Psychological and social aspects of pain. British Journal of Nursing 2001; 10: 903-11

15. Melzack R, Wall PD. Pain mechanisms: a new theory. Science. 1965; 150:971-79.

16. Melzack R, Casey K. The skin senses. Springfield: Charles C. Thomas; 1968. Sensory, motivational, and central contol determinants of pain; p. 423-43.

17. Moayedi M, Davis KD. Theories of pain: from specificity to gate control. J Neurophysiol. 2013 Jan; 109 (1): 5 12. doi: 10.1152/jn.00457.2012.

18. Katz J, Rosenbloom BN. The golden anniversary of Melzack and Wall's gate control theory of pain: Celebrating 50 years of pain research and management. Pain Res Manag 2015 Nov-Dec; 20 (6): 285-6. doi: $10.1155 / 2015 / 865487$.

19. Özveren H. Ağrı kontrolünde farmakolojik olmayan yöntemler. Sağlık Bilimleri Fakültesi Hemşirelik Dergisi 2011: 83-92.

20. Fernandez E. A classification system of cognitive coping strategies for pain. Pain, 1986; 26: 141-51.

21. Hudson BF, Ogden J, Whiteley MS. Randomized controlled trial to compare the effect of simple distraction interventions on pain and anxiety experienced during conscious surgery. Eur J Pain 2015; 19 (10): $1447-55$. doi: 10.1002/ejp.675

22. Umezawa S, Higurashi T, Uchiyama S, et al. Visual distraction alone for the improvement of colonoscopyrelated pain and satisfaction. World J Gastroenterol 2015; 21: 4707-14.

23. Hudson BF, Ogden J. Exploring the impact of intraoperative interventions for pain and anxiety management during local anesthetic surgery-A systematic review and meta-analysis. Journal of PeriAnesthesia Nursing 2016; 31 (2): 118-33

24. Honzela E, Murthib S, Brawn-Cinanic B, et al. Virtual reality, music, and pain: Developing the premise for an interdisciplinary approach to pain management. PAIN 2019; 160 (9): 1909-19. doi: 10.1097/j.pain.0000000000001539.

25. Mosso Vázquez JL, Mosso Lara D, Mosso Lara JL, Miller I, Wiederhold MD, Wiederhold BK. Pain distraction during ambulatory surgery: Virtual reality and mobile devices. Cyberpsychology, Behavior, and Social Networking 2018; 22 (1): 15-21. doi:10.1089/cyber.2017.0714 
26. Jameson E, Trevena J, Swain N. Electronic gaming as pain distraction. Pain Res Manag 2011 Jan-Feb; 16 (1): 27-32. doi: 10.1155/2011/856014.

27. Pavlin JD, Chen C, Penaloza DA, Polissar Nayak L, Buckley FP. Pain as a factor complicating recovery and discharge after ambulatory surgery. Anesthesia \& Analgesia 2002; 95 (3): 627-34. doi: 10.1213/00000539200209000-00025

28. Sogabe M, Okahisa T, Adachi, Y. et al. The influence of various distractions prior to upper gastrointestinal endoscopy: a prospective randomized controlled study. BMC Gastroenterol 2018: 18; 132. https://doi.org/10.1186/s12876-018-0859-y

29. Pereira L, Figueiredo-Braga M, Carvalho IP. Preoperative anxiety in ambulatory surgery: The impact of an empathic patient-centered approach on psychological and clinical outcomes. Patient Educ Couns 2016; 99: 733-8.

30. https://www.kickstarter.com/projects/antsylabs/fidget-cube-a-vinyl-desk-toy, Erişim tarihi: 11.07.2020

31. Lee CH, Liu JT, Lin SC, Hsu TY, Lin CY, Lin LY. Effects of educational intervention on state anxiety and pain in people undergoing spinal surgery: A randomized controlled trial. Pain Management Nursing 2018; 19 (2): 163-71.

32. Erden S. Cerrahi ağrıda bakım. Karadağ M., Bulut H. Cerrahi Hemşireliği 1. Vize Basın Yayın 2019, Ankara.syf. 127

33. Aydemir Ö, Köroğlu E. Psikiyatride sık kullanılan ölçekler. Hekimler yayın birliği 2006, Ankara.

34. Urbaniak GC, Plous S. Research Randomizer (Version 4.0) [Computer software]. 2013, Retrieved on 17 Ocak, 2019, from http://www.randomizer.org/

35. Phelan I, Furness PJ, Fehily O, et al. A mixed-methods investigation into the acceptability, usability and perceived effectiveness of active and passive virtual reality scenarios in managing pain under experimental conditions. J Burn Care Res 2019 Jan 1; 40 (1): 85-90. doi: 10.1093/jbcr/iry052.

36. Kılıç S. Effect size. Journal of Mood Disorders 2014; 4 (1): 44.

37. Molleman J, Tielemans JF, Braam MJ, Weitenberg B, Koch R. Distraction as a simple and effective method to reduce pain during local anesthesia: A randomized controlled trial. Journal of Plastic, Reconstructive \& Aesthetic Surgery 2019; 72 (12): 1979-85

38. Yılmaz D, Güneş ÜY. The effect on pain of three different nonpharmacological methods in peripheral intravenous catheterisation in adults. J Clin Nurs 2018; 27: 1073- 80. https://doi.org/10.1111/jocn.14133)

39. Gezginci E, Iyigun E, Yalcin S, Bedir S, Ozgok IY. Comparison of two different distraction methods affecting the level of pain and anxiety during extracorporeal shock wave lithotripsy: A randomized controlled trial. Pain Management Nursing 2018; 19 (3): 295-302

40. Yanes AF, Weil A, Furlan KC, Poon E, Alam M. Effect of stress ball use or hand-holding on anxiety during skin cancer excision: A randomized clinical trial. JAMA Dermatol 2018; 154 (9): 1045-49. doi:10.1001/jamadermatol.2018.1783

41. Nordahl $\mathrm{H}$, Hjemdal $\mathrm{O}$, Hagen R, Nordahl HM, Wells A. What lies beneath trait-anxiety? Testing the selfregulatory executive function model of vulnerability. Frontiers in psychology 2019; 10 (122): 1-8.

42. Kabakçı E. Panik ve yaygın anksiyete bozukluklarında bilişsel-davranışçı tedaviler. Editörler: Savaşır I., Soygüt G., Kabakçı E. Bilişsel-davranışçı Terapiler. 3. Basım. Ankara: Türk Psikologlar Derneği Yayınları; 2003: 91-92.

43. Erden S, Demir N, Ugras GA, Arslan U, Arslan S. Vital signs: Valid indicators to assess pain in intensive care unit patients? An observational, descriptive study. Nurs Health Sci 2018; 20 (4):502-8. doi:10.1111/nhs. 12543

44. Rey AE, Michael GA, Dondas C, Thar M, Garcia-Larreal, Mazza S. Pain dilates time perception. Sci Rep 2017 Nov 16; 7 (1): 15682. doi:10.1038/s41598-017-15982-6.

45. Bar-Haim Y, Kerem A, Lamy D, Zakay D. When time slows down: The influence of threat on time perception in anxiety. Cognition and Emotion 2010; 24 (2): 255-63. https://doi.org/10.1080/02699930903387603

46. Schneider SM, Hood LE. Virtual reality: A distraction intervention for chemotherapy. Oncol Nurs Forum 2007; 34 (1): 39-46.

47. Schneider S, Kisby C, Flint E. Effect of virtual reality on time perception in patients receiving chemotherapy. Supportive Care in Cance 2011; 19 (4): 555-64. DOI: 10.1007/s00520-010-0852-7

48. Finlay KA, Anil K. Passing the time when in pain: Investigating the role of musical valence. Psychomusicology: Music, Mind, and Brain 2016; 26 (1): 56-66. 